\title{
«Quería probar que puedo hacer tendencia». Activismos ciudadanos online y prácticas poplíticas en el Perú
}

\author{
Raúl Castro Pérez \\ Universidad Científica del Sur \\ ccastroperez@cientifica.edu.pe
}

RESUMEN

En la última década se ha venido analizando el modo como la participación política y la movilización ciudadana sustentan su organización en el uso de los social media. Se enfocan en la creciente interactividad que facilitan plataformas como Facebook, YouTube o Twitter, y en los activismos y protestas masivas que surgen con ellos, retroalimentados con marchas y tomas de espacios públicos. Se trata de activismos episódicos, centrados en causas puntuales, sin militancia de sus participantes en partidos formales, que ejercen reclamos por derechos básicos o protestas contra arbitrariedades de poderes nacionales o locales. ¿Pueden estas movilizaciones y sus repertorios expresivos - activismo digital, performances en calles $y$ plazas y eficientes estrategias mediáticas-calificarse como prácticas poplíticas? El presente artículo propone englobarlos en este concepto, postulando un modelo interpretativo a partir del análisis de dos casos peruanos: Meme No y Alerta de policías con cámaras de velocidad, mediante el estudio de las narrativas personales de sus activistas y el análisis de contenido de los recursos utilizados, en particular de sus memes y su despliegue viral.

Palabras clave: protesta social, activismo político, movilización ciudadana, social media, meme, viral, poplítica. 


\section{«I Wanted to Prove that I Can Make Trend». Online Citizen Activisms and 'Poplitical' Practices in Peru}

\section{ABSTRACT}

During the last decade, the way social media is structuring contemporary political participation and citizen mobilization was been discussed. Studies focus on the raising interactivity that platforms like Facebook, YouTube or Twitter facilitate, as well as massive protest and activism that emerge from them, in sinergy with square and street movements. Studies refer to episodic activisms that target banal goals and have no formal militance in political parties, exercising actions against arbitrary decisions of everyday power. May these mobilizations, and their expressive repertoires, like performances and media strategies, be labelled as poplitic practices? The present article uses that concept as an interpretive model for the analysis of two Peruvian case studies: Meme No and Alerta contra policias con cámaras de velocidad ("Alert of Police with Speed Cameras»). In the search for the digital storytelling of their activists, and in the content analysis of their resources, like memes and viral processes, the present article will dimension the actual height of mobilizations.

Keywords: social protest, political activism, citizen mobilization, social media, meme, viral, poplitic. 


\section{INTRODUCCIÓN}

El disgusto en América Latina por la calidad de sus instituciones políticas y por la corrupción en la gestión de sus asuntos públicos ha venido creciendo de modo preocupante en la región (Carlin, Singer y Zeigmeister, 2015). Este estado de ánimo se ha visto reflejado en numerosas manifestaciones ciudadanas que, como se ha venido documentando, se expresan tanto en los tradicionales espacios urbanos de calles y plazas, tomados activamente, como en los nuevos escenarios de los medios sociales digitales, llámense Facebook, Twitter o YouTube. Así, hemos visto movilizaciones masivas como las protestas estudiantiles de Chile (Scherman et al., 2013), las crisis sociales en Brasil en el contexto del mundial de fútbol (Porto et al., 2015; Bastos et al., 2014) y las marchas contra una ley de empleo juvenil en el Perú (Fernández-Maldonado, 2015), que han sido expresiones elocuentes de ello, mostrando también en su despliegue una marcada renovación de los actores políticos, así como consignas inéditas centradas en la defensa de valores y principios ciudadanos básicos como la transparencia, la honradez y la decencia.

Movilizaciones como estas se vienen dando con regularidad en el Perú y empiezan a ganar peso político. Para abordar el tema, el presente artículo se focalizará en el análisis de dos movimientos en particular: el colectivo de activistas digitales de Meme No y el grupo Alerta contra policías con cámaras de velocidad, así como en las prácticas de protesta y acción que desplegaron. Por un lado, el colectivo Meme No fue clave para evitar el proceso de revocatoria que afrontó la entonces alcaldesa de Lima, Susana Villarán, en 2013. Por otro, la movilización de los activistas de Alerta contra policías con cámaras de velocidad logró suspender un programa municipal de multas a conductores de autos, develando la corrupción con la que esta se estuvo ejecutando.

En el análisis de estos casos, examinaremos en particular las historias de algunos activistas que animaron sus organizaciones y las formas en que emplea- 
ron sus recursos en los distintos entornos mediáticos en los que se desenvolvían. Toda vez que ambas cuestiones - un proceso de revocatoria turbio y un programa municipal corrupto - los afectaban en sus espacios más personales, también apreciaremos la dimensión cotidiana que su activismo cobró y el impacto que este tuvo en sus sentidos de orden social inmediato. Sostenemos que este es el campo de la poplitica actual.

Consideramos la poplítica como la expresión de una forma de ejercer participación ciudadana con las claves de la cultura pop propia de los medios de comunicación, en particular, de los códigos y lenguajes del social media. Contempla visibles acciones públicas de sujetos sociales altamente empoderados — ciudadanos conscientes de la plenitud de sus derechos y deberes-y con mucha voluntad para comprometerse en causas específicas propiciatorias de renovados sentidos comunitarios. Este artículo explorará estos giros en la cultura política de amplios sectores ciudadanos, recurriendo a testimonios de activistas cuyos intereses están explícitamente alineados con las nuevas narrativas colectivas que están surgiendo, y que comparten prácticas mediáticas gracias al contagio que se propicia con la lógica viral de los medios sociales.

\section{DE LOS «E-MOVIMIENTOS» A LAS «E-MOVILIZACIONES»: UN ESTADO DE LA CUESTIÓN}

Desde marchas masivas que toman ciudades hasta movilizaciones barriales ante un conflicto residencial, los estudios destacan cómo el activismo en plataformas digitales juega un rol dinamizador en ellas, en especial cuando trascienden el clicktivismo (Karpf, 2010; Halupka, 2018) y propician manifestaciones en plazas y espacios públicos (Gerbaudo, 2012; Kavada, 2015; Yang, 2016). Se destaca, entonces, un cambio cualitativo y cuantitativo en el uso de estas nuevas herramientas: las movilizaciones son más que una suma de miles de iniciativas y coincidencias. Las multitudinarias acciones de individuos y grupos sincronizan para configurar movimientos online cuyo trabajo de base se da sobre una ecología continua que va del «cara a cara» local hasta los entornos digitales transnacionales. Es lo que Earl y Kimport establecen como el surgimiento de los e-movimientos (2011).

Los autores destacan también el lugar central que cobran las plataformas digitales como escenario y sistema de relacionamiento a la vez, lo que permite que la voluntad participativa de miles de ciudadanos autónomos se concrete mediante actividades en foros y operativos diversos. En estas condiciones, sus movilizaciones comparten rasgos comunes: una o varias causas de índole moral 
como fundamento principal, estéticas e iconos compartidos por diferentes movimientos en el mundo - algo que llama la atención, dada la dispersión geográfica y social de los participantes-, y el carácter repentino de sus acciones, así como lo efímero de sus asociaciones. Con ello, destacan los mencionados motores tecnológicos por medio de los cuales los activistas transforman sus acciones colectivas en «diagramas de contagio» propalados con sus propias interacciones (Parikka, 2007).

Postill (2013, 2014), Kavada (2015) y Gerbaudo y Trere (2015), entre otros autores, coinciden al señalar que el año 2011 marcó un punto de inflexión para estas nuevas formas de movilización: tres grandes acciones en distintas partes del mundo señalaron el inicio del nuevo activismo político ciudadano, con enorme poder de transformación. Por un lado, en Egipto - como antes había ocurrido en Túnez, y luego en Libia y Yemen-, la explosión social conocida como la Primavera Árabe fue generada por individuos y grupos interconectados que golpearon a regímenes dictatoriales de larga dominación, articulando a activistas de distinta condición y procedencia mediante un creciente uso de redes sociales (Castells, 2012). Para Monteverde et al. (2015), por otro lado, el denominado Movimiento $15 \mathrm{M}$ en España, también conocido como los indignados, se desencadenó el mismo año como parte de una ola de nuevos grupos de presión conectados a través de medios digitales que compartían similares reclamos de postergación social. Según Postill, estos grupos conforman un conjunto emergente de actores sociales que comparten la condición de «tecnólogos de libertad» (2018).

Los movimientos en Egipto y España fueron decisivos para sentar nuevas formas de movilización. Pero cuando la organización Occupy Wall Street tomó el parque Zuccotti en el centro de Manhattan, en Estados Unidos, en septiembre de 2011, y se expandió luego a 1000 ciudades de todo el mundo (Costanza-Chock, 2012, citado en Kavada, 2015), replicando consignas, estéticas y prácticas, el fenómeno de las movilizaciones digitales escaló hasta ser ahora la condición general de distintas acciones colectivas. Desde entonces, también, los investigadores consideran que estos despliegues estratégicos forman parte de nuevas culturas políticas compartidas a las que Gerbaudo llama «movimientos de plazas (Gerbaudo, 2012). Son, por tanto, prácticas reivindicatorias en las que sujetos convergen e inciden en nuevos balances de poder frente a las autoridades, y cuyas características distintivas son «la ocupación del espacio público, la falta de líderes reconocibles, un énfasis en la inclusión y la creencia en la democracia y la justicia» (Kavada, 2015, citando a Castells, 2012 y Juris, 2012). 
Los autores señalan que, tras la caída del radicalismo político popular en la década de 1970, lo que apareció en su lugar ha sido una «sociedad de movimientos sociales donde la protesta se ha hecho cada vez más institucionalizada y cívica, antes que perturbadora» (Yang, 2016). Las demandas se han hecho paulatinamente cada vez más pedestres y surgió con ello la política de asuntos cotidianos y residenciales. Postill lo denomina el surgimiento de la «política banal», en el sentido de la política de los asuntos de la vida diaria (Postill, 2013). En esta perspectiva, el activismo cívico se «rutiniza», y se hace parte del repertorio común de los ciudadanos (Postill, 2013; Yang, 2016).

Hoy las asociaciones de vecinos o juntas de propietarios son habituales y forman parte de la vida diaria de los ciudadanos. Los reclamos por malos servicios, la denuncia de autoridades corruptas o el mal uso del espacio público, registrados generalmente en imágenes de cámaras del móvil, son usos rutinarios de las potestades ciudadanas. Dichos actos encuentran canales de diseminación, una vez más, en las plataformas digitales, tanto como en espacios de relación «cara a cara».

Es este el espacio de la poplítica. Si entendemos la política como el campo propio de las instituciones de gobierno y de los debates y conflictos alrededor de ellas (Miller et al., 2016; Sartori, 2002), cuyo propósito es acceder al poder o influir sobre él (Dahl, 1957; Naím, 2013), entonces la práctica cotidiana de monitorear, retar o cuestionar a la autoridad institucional es igualmente política, aun cuando se dé en un terreno habitual y de asuntos comunes. Claro está que los escenarios, escalas y fines son otros: ya no son solo — ni prioritariamente- los que se dan frente al Parlamento o a los órganos de gobierno ejecutivo, sino los que se dan frente a los micropoderes instalados en la vida ordinaria.

Este es el régimen de la poplítica: el de la política de la cultura popular. Es el activismo de todos los días de causas ciudadanas, sean estas la indignación por valores corroídos o acciones contra poderes que están afectando a la persona de inmediato. Este activismo se expresa mediante despliegues performáticos, con frecuencia usando recursos artísticos, y con códigos y lenguajes propios de la cultura de medios de comunicación que facilitan la proyección pública de sus malestares. Por eso, cada acción se entiende también como una actuación codificada para sintonizar con grandes audiencias, representada conscientemente como un montaje narrativo de varias nanohistorias que, juntas, logran hacer tendencia. 


\section{TRAZANDO NARRATIVAS DIGITALES: PAUTAS METODOLÓGICAS}

Cuando Sarah Pink y John Postill plantean en Social Media Ethnography: The Digital Researcher in a Messy Web (2012) que un estudio etnográfico hoy en especial el que investiga la interacción entre las personas y los medios de comunicación - debe también analizar el comportamiento que registran estas personas en los medios digitales, están estableciendo una nueva normalidad: el uso de redes sociales digitales como parte constitutiva de nuestra cotidianidad. Más aún, constituyente de la noción misma de realidad que experimentamos, en tanto forma parte de sistemas más amplios de relaciones y entornos que ordenan nuestras experiencias en la vida diaria (Pink, Horst et al., 2016).

En este contexto, entendemos que las interacciones que efectúan las personas en los medios sociales no son aleatorias. Responden, por el contrario, a lógicas personales coherentes y consistentes, en tanto expresan relatos plenos de sentidos expuestos, adrede, públicamente (Haynes, 2016). Por ello es que investigadores como Vivien (2016) o Barassi (2017) ponen atención a las dimensiones personales y afectivas de las publicaciones online de los sujetos, focalizando sus análisis en los recursos narrativos que utilizan y en su capacidad para conformar relatos digitales de identidad articulados con otros como ellos.

Siendo así, este artículo pondrá atención, precisamente, en las dimensiones emocionales de los relatos biográficos de los activistas bajo análisis. En tal sentido, se explorará en las distintas formas en que los medios sociales son usados por ellos y en cómo utilizan sus conocimientos profesionales y sus habilidades tecnológicas y sociales para impulsar las causas que promueven, así como qué sentido tiene todo esto para ellos. Con esa intención, conversé con cuatro activistas y repasé con ellos sus historias de vida con la finalidad de identificar los trazos que vinculen sus trayectorias con los relatos generales de las causas que defienden.

Pongo particular atención en su empleo de memes, es decir, en las viñetas o recursos gráficos que los activistas utilizaron como un vehículo clave de su comunicación y expresión pública. En esa línea, realizo análisis de contenido de dichos recursos, observando no solo quién los publica y con qué pretensión, sino también identificando al personaje que los protagoniza, el guion que interpreta y los significados políticos, sociales y culturales que comprenden, en tanto los memes, a menudo, se animan con personajes populares y sus frases más icónicas. Se tratará también de comprender la relación entre la evocación que suscitan estos personajes en la vida cotidiana de los activistas y lo que representan dentro de una reflexión más general sobre el orden social en el que se desenvuelven. 
Siguiendo el trabajo de Haynes (2016), indago en lo que los memes representan, en su relevancia sociológica y, sobre todo, en su rol como espacios reflexivos. Exploro el uso de la parodia que ejercen y en el sentido de identificación y pertenencia que expanden en grupos de ciudadanos con quienes el mensaje sintoniza. El sentido moralista subyace con regularidad en estas movilizaciones, razón por la cual la indagación se fija también en la voz que asume la representación -es decir, el carácter del meme - y en el tipo de reflexión que encarna en particular, así como en las distinciones que marca frente a otros a quienes alude por oposición, sea esta ideológica, partidaria o de principios.

En el análisis de contenido, sigo pautas dadas por Shifman (2014) para el estudio de los memes en las culturas digitales. Implemento una heurística sobre la base de las cuatro pautas que propone: (i) las políticas de participación: quiénes son los actores y qué performances tienen, en entornos digitales y no digitales; (ii) el lenguaje que emplean: los niveles compositivos, sintácticos y semánticos que despliegan; (iii) el análisis de quehacer político: acciones y discursos que contextualizan su difusión, y (iv) sus resultados comunicacionales, es decir, su grado de viralidad: el análisis de sus réplicas y copiado.

Sobre la viralización, se recurre a Postill y a las pautas que establece en el análisis de fenómenos de movilización similares: a su propuesta de Media Epidemiography (2014). Vamos a emplear esta como una «heurística para explorar la rápida evolución del campo tecno político en el que se despliegan hoy las luchas populares» (Postill, 2014). Esta definición es fundamental para la comprensión del activismo digital en el Perú de hoy, pues coloca en el centro del análisis la especial capacidad que tienen ahora las movilizaciones para propiciar debate y buscar el cambio social, gracias a su poder de propagación (Nahom y Hemsley, 2013).

\section{PRÁCTICAS POPLÍTICAS EN EL PERÚ: «QUERÍA PROBAR QUE PUEDO HACER TENDENCIA»}

Si 2011 fue un año clave para el activismo ciudadano en el mundo, en el Perú ese año fue 2013. Dos acontecimientos distintos: uno propio de hechos políticos generales, como fue el primer intento de revocatoria contra la alcaldesa de Lima mediante un referéndum, y una rauda - y contundente - movilización de miles de ciudadanos indignados ante la corrupción manifiesta en la Policía y la comuna de Lima durante la aplicación de una nueva política de multas por exceso de velocidad a los conductores de automóviles mostraron cómo también en el Perú las movilizaciones ciudadanas - ahora potenciadas con herramientas digitales - 
entraban en una nueva etapa y sintonizaban con el ambiente de activismo popular y masivo actualmente extendido.

En los casos tratados a continuación, el protagonismo de activistas sin formación política previa ni experiencia partidaria fue preponderante. ¿Qué marcó su poder de movilización? Principalmente, su manejo de herramientas de influencia sobre la opinión pública, tanto como su competencia en el uso de sistemas tecnosociales de movilización de medios digitales. En ambos casos, sus acciones motivaron también cambios considerables en el orden político local del momento y en las formas en las que autoridades y clase política en general entienden ahora lo que es rendir cuentas ante la ciudadanía.

\section{La plataforma Meme No}

El caso Meme No es ilustrativo de estos nuevos procesos. Empezó como una cuenta de Facebook, creada por los publicistas Ricardo Solano y Henry Urrunaga en un intento deliberado de influir en la marcha de los acontecimientos que, según propia confesión, los «indignaban» (entrevista personal, 21 de marzo de 2013). Al momento de activar la cuenta, ellos ejercían como escritor creativo y diseñador gráfico, respectivamente, en una importante agencia peruana. Y se puede considerar que fueron dos importantes maquinistas de un tren que, al final de la campaña, logró descarrilar el proceso de revocatoria emprendido contra la alcaldesa de Lima de ese entonces, Susana Villarán, el año 2013. Vale decir que, desde la conclusión de su mandato, en 2016, Villarán viene afrontando distintos procesos legales por presuntos aportes no declarados de constructoras brasileñas precisamente para financiar sus campañas, entre ellas la de la revocatoria en su contra ${ }^{1}$.

La cuenta de Facebook Meme No fue creada en 2012 con el fin de «crear tendencia» (entrevista personal, 21 de marzo de 2013). La cuenta continúa vigente, aunque tras la campaña del No derivó en un sitio de humor político y comen-

\footnotetext{
Susana Villarán está siendo investigada desde 2017 por presunto desbalance no justificado en sus declaraciones de aportes a la campaña electoral con la que ganó las elecciones municipales de 2012, así como por la mencionada campaña en contra de su revocatoria, conocida como la campaña del No. Según el diario El Comercio, «la fiscalía considera otros elementos, como un desbalance entre los aportes que declaró la campaña del No y los ingresos y gastos reales que detectó el Ministerio Público, así como visitas de representantes de Odebrecht y OAS a la comuna durante el proceso de revocatoria». Consulta hecha en El Comercio: https://elcomercio.pe/politica/susana-villaran-situacion-allanamiento-fiscal-analisis-noticia-509888. La investigación, por supuesto, causó profunda decepción y deslinde entre quienes participaron en su campaña.
} 
tario de la coyuntura. Por definición de sus creadores, surge como un proyecto de comunicación política creativa sustentado en la crítica corrosiva, buscando capturar la complicidad de ciudadanos que se encontraban igualmente indignados con el intento de operadores políticos del partido perdedor de la justa electoral de 2012: Solidaridad Nacional, de echar a la alcaldesa. La justa fue ganada por Villarán en una disputa muy apretada.

Cuando la campaña de revocatoria comenzó, en 2012, la opción del Sí (o sea, la revocación del mandato de la alcaldesa) estaba casi treinta puntos por encima de la opción del No. Entonces, el equipo de publicistas de la alcaldesa convocó a varias personalidades con influencia en la opinión pública: políticos, intelectuales y artistas, a apoyarla en su causa. Muchos de ellos asumieron el reto tomándose retratos sencillos para una campaña de paneles publicitarios en la vía pública junto a la palabra No. También deportistas, chefs y otras celebridades, entre una vasta diversidad de adherentes, asumieron el llamado, y sus imágenes fueron distribuidas de forma muy visible por toda la ciudad. Los paneles eran estéticamente simples, y desde su diseño original ya adoptaban el formato estándar de los memes. Esto es: la imagen única de un sujeto protagonista con fondo blanco, y un breve eslogan en destaque, y en el que, para el caso de esta campaña, sobresalía la palabra $\mathrm{No}^{2}$.

La alcaldesa no gozaba entonces de mucha simpatía. Era muy cuestionada por una supuesta inconsistencia entre sus discursos y sus acciones reales, lo cual le valió apelativos como «Lady Vaga» o «Tía Lentejita», que apuntaban a mostrarla sin capacidad de resolución. Sin embargo, para muchos otros ciudadanos, un referéndum para revocarla a un año de iniciado su gobierno era un exceso, pues no le permitiría concretar lo que había anunciado. Sus defensores lo consideraban un mal mecanismo legal, pues jaqueaba prematuramente las gestiones y se prestaba a ser utilizado por grupos con intereses particulares. En esa línea, precisamente, la campaña se convirtió en una serie de ataques personalistas y desagradables, con informaciones sesgadas e insultos para desprestigiar aún más la ya desgastada imagen de la alcaldesa.

2 Los medios de comunicación documentaron, en aquel momento, el arranque de la campaña, con artículos y reportajes diversos. Dos medios online ofrecen buenos resúmenes: el blog Anuncio, luego existo, de Alexander Chiu, con la entrada «La campaña por la revocatoria», en: http://blogs.gestion.pe/anunciasluegoexistes/2013/02/la-campana-por-la-revocatoria.html, y el informativo Terra, con la entrada «Los cerebros de la campaña del No en redes. Facebook y memes», en: https://noticias.terra.com.pe/peru/revocatoria-de-susana-villaran/los-cerebrosde-la-campana-del-no-en-redes-memes-y-facebook,0e5763a02338d310VgnVCM20000099cceb0aRCRD.html 
Es este contexto surge Meme No. Y no fue el único: surge junto a otras cuentas similares, como Los rostros del No, Lima No Para, o 40 veces No, las que, entre todas, consiguieron masificar su mensaje y propiciar una ola que se expandió velozmente. En este contexto se inició esta investigación, para lo cual busqué reunirme y conversar con los principales actores. Así, una mañana de marzo de 2013 me reuní con Ricki Solano y Henry Urrunaga en un café cercano a su centro de trabajo. Mi intención era encontrar relevancia sociológica en sus narrativas de identidad personales y profesionales y entender con ellos cómo sus incursiones repentinas en el activismo ciudadano conformaban procesos más amplios y generales de nuevas subjetividades políticas.

En la conversación, Solano, uno de los dos gestores de la cuenta, anticipó dicha relevancia: su motivación original para el lanzamiento de la campaña fue el desafío profesional de hacer tendencia, buscando, al mismo tiempo, mitigar la indignación despertada en ellos - y en lo que percibían de su entorno- mediante una campaña manejada con los principios básicos de todos sus proyectos publicitarios: una campaña de activación digital. Según comenta:

Empezamos a hacer memes como una forma de burla a la situación y los compartimos en nuestros muros. Era como hacer deporte, para demostrarnos a nosotros mismos que podíamos penetrar en internet, dejar huella en las redes y manipular la comunicación. Queríamos probar que podíamos hacer tendencia» (entrevista personal, 21 de marzo de 2013).

Solano y Urrunaga empezaron difundiendo los memes en la cuenta Meme No - lanzada el 1 de febrero de 2012 - y de inmediato los rebotaban a través de sus propias cuentas personales. Priorizaron el Facebook por tratarse de una red social donde la visualidad tiene un rol preponderante: «El Facebook es el lugar del meme por excelencia», dice Urrunaga. Así, aplicaron en su campaña la estética clásica del meme digital, usando básicamente imagen y texto, componiéndolos con los tres elementos resaltantes: (i) la palabra No en color celeste; (ii) una frase célebre de alta recordación en medios masivos, es decir, en películas, música pop o programas de TV, y (iii) la imagen del personaje que hizo popular la frase sobre el fondo blanco. Todo ello parodiando la estética de los paneles mencionados.

Así, los mensajes de Meme No conformaron una campaña protagonizada por personajes muy populares de las culturas mediáticas y por expresiones de alta recordación para jóvenes y adultos usuarios de dichos medios. Sobre ello, en una entrevista posterior, dijo Solano: «Nos enfocamos en sus insights más reconocibles» (entrevista personal, 14 de noviembre de 2014). Por ejemplo, el meme con la imagen de Don Ramón —el célebre personaje de la serie El Chavo del Ocho — se exhibió 
junto a su popular frase «NO te doy otra nomás». Fue uno de los más populares, pero no el primero: Solano y Urrunaga recuerdan que el primero fue el de Darth Vader, el oscuro personaje de Star Wars, gritando «NOOOOOO» como en una de sus líneas de las películas. Otro meme inicial de convocatoria - digamos, un llamado generacional - fue el del popular Bebé Sinclair, personaje de la serie de TV para niños Dinosaurios, vocalizando su canción «NO La Mamá».

\section{Figura 1}
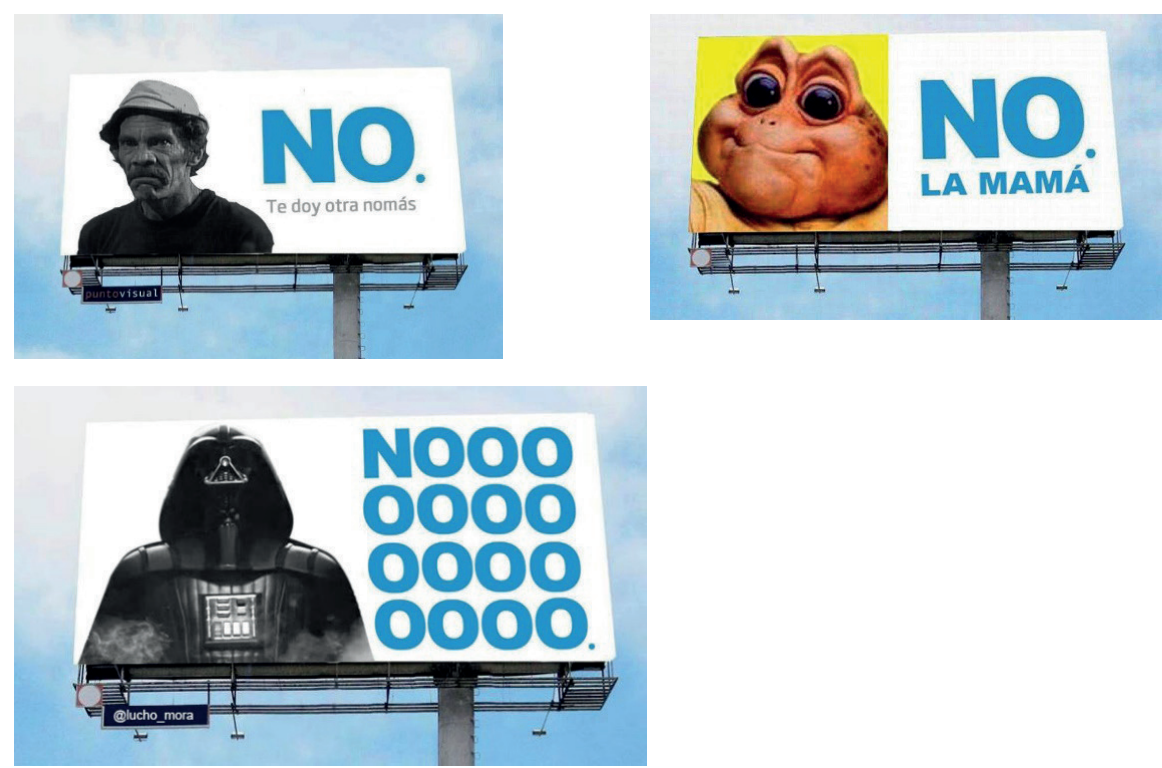

Solano y Urrunaga sostienen que ellos buscaban «aligerar la campaña, quitarle la seriedad y lo aburrido, e inyectarle algo de humor» (entrevista personal, $14 \mathrm{de}$ noviembre 2014). En ese ejercicio, eran conscientes de que estaban empleando sus conocimientos y habilidades más probados, así como los códigos y lenguajes más recurrentes en medios de comunicación, para conseguir la mayor eficiencia en sus propósitos. Del mismo modo, sabían que sus activaciones digitales también tendrían consecuencias directas sobre las simpatías e intención de voto. Describe Solano:

Queríamos llamar la atención y, luego, enviar un mensaje. Capitalizamos lo que ya existía en la conciencia colectiva de las personas y cambiamos la connotación del No hacia algo positivo. De esta manera, mucha gente se interesó en el tema, que era un tema beligerante y de confrontación pero que 
gradualmente se convirtió en algo más coloquial, más entretenido y que generaba debate (entrevista personal, 21 de abril de 2015).

Solano y Urrunaga son jóvenes nacidos en los primeros años de la década de 1990, con formación profesional en universidades privadas el Perú. Sus lugares de residencia: San Miguel y Surco, así como su escolaridad en colegios de paga, son indicadores de su condición de clase media. En los días de Meme No ya eran profesionales solicitados que trabajaban en una de las principales agencias transnacionales de publicidad en Lima. Contaban ya con alguna actividad política en la universidad, en acciones estudiantiles, pero nada más después de ello. Es recién con el malestar del referéndum cuando deciden hacerse un tiempo en sus rutinas laborales para activar la cuenta, iniciar acciones y «revisar los likes, viendo qué publicación pegó más, y la cantidad de fans» (entrevista personal, abril de 2015). Es decir, lo que se hace con toda cuenta de publicidad corporativa. "Cuando haces este tipo de página - explica Solano - estás a la expectativa de todo esto. Es el morbo de saber cuánto influyes en la gente» (entrevista personal, abril de 2015).

Solano cree que su incursión en el activismo se incubó durante su época universitaria, «en el gremio estudiantil, con las elecciones universitarias... Cuando formaba parte de algún movimiento, la gente debatía en blogs y me di cuenta de que eso era absurdo. Aquí la efervescencia política te picaba la mano, y me di cuenta de que tenía que actuar con algo como Meme No, con la cabeza fría, más tranquilo, sentado frente a una $\mathrm{PC} \gg$ (entrevista personal, abril de 2015).

Las intuiciones de Solano fueron certeras en tanto la cuenta logró tener más de 124000 seguidores en muy poco tiempo de actividad. Su «travesura» logró establecer marcada empatía con los electores más jóvenes, particularmente entre los que están inmersos en experiencias online y en la práctica de contenido autoelaborado. Por ello sus seguidores no solo se identificaron con sus mensajes, sino que también se animaron a crear sus propios memes siguiendo la tendencia. Fue el caso de Pierre Castro, entonces también diseñador gráfico en otra importante agencia de publicidad, pero sin contacto ni conocimiento personal con Solano y Urrunaga. «Es que ni bien sale elegida Susana, ya la empiezan a molestar», explicaba Pierre, por lo cual, confiesa, todo el proceso de revocatoria le producía «una aversión muy fuerte»:

No es que haya estado comprometido en la campaña a favor de Susana. Solo me pareció que había que apoyarla. Confiaba en ella, así que empecé a hacer estos memes que se me iban ocurriendo, creo que hice como diez en un solo día. Los iba subiendo a la red, y mis amigos, a la vez, también iban subiendo otros (entrevista personal, julio de 2017) 
En ese contexto, el uso paródico de personajes locales e internacionales se hace intensivo. Pierre recuerda haber compuesto un meme con Manolito, el personaje de Mafalda, así como los memes de icónicos baladistas españoles como Nino Bravo o Julio Iglesias (compartidos centenares de veces). En especial recuerda el de una popular imagen de Batman, en la que el superhéroe da una cachetada a Robin, con la frase: «NO, carajo!». «Fueron mis primeros memes», evoca. Años después, Pierre sería protagonista de la noticia como un profesor universitario reconocido por emplear, justamente, memes, y otros recursos digitales como recursos pedagógicos.

\section{Figura 2}
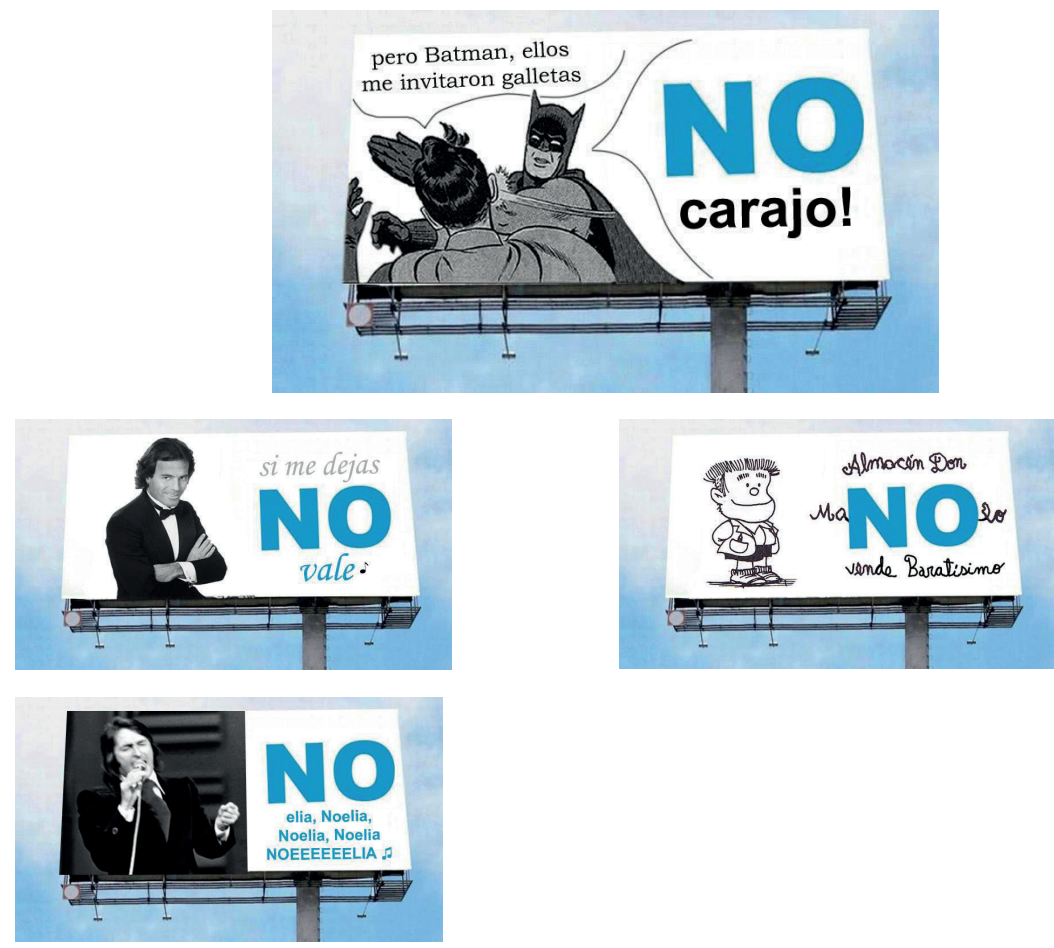

Pierre es comunicador publicitario egresado de una universidad privada de la capital. Si bien en esta universidad está prohibida la actividad política, se familiarizó con el activismo político, como Solano, gracias a su padre. Su padre es ingeniero de la universidad pública de Trujillo, quien «era muy comprometido con la política, siempre con la radio prendida, siempre con periódicos en la mesa» (entrevista personal, julio de 2017). 


\section{Figura 3}
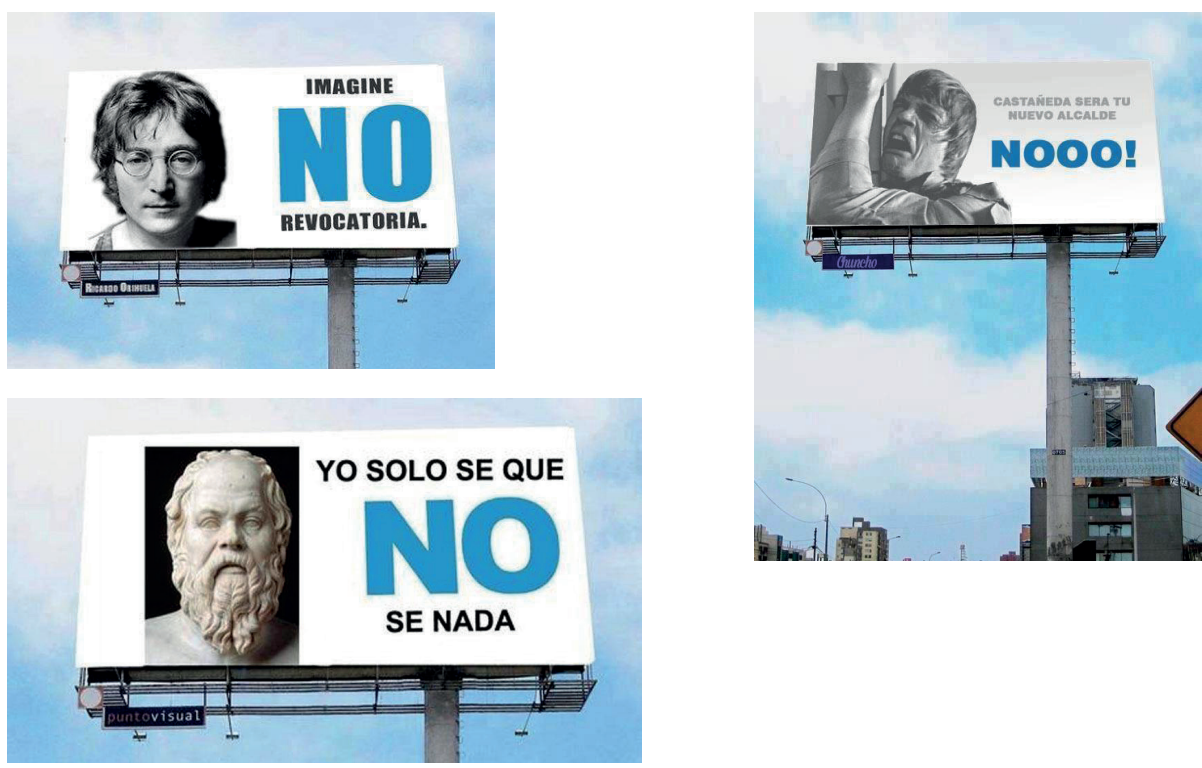

Como él, colegas y amigos se sumaron a la fuerza viral del Meme No, sin conocer o tener vínculo alguno con los administradores de la cuenta. Aparecieron entonces memes, por ejemplo, de John Lennon, diciendo: «Imagina que NO hay revocatoria» o Paul McCartney diciendo: "You Say Yes, I Say NO». Imágenes de Luke Skywalker, César del Planeta de los Simios, y Gandalf de El Señor de los Anillos también fueron empleadas usando la palabra NO en el contexto de las escenas más conocidas de las películas. Incluso un busto del filósofo griego Sócrates cobró vida con la frase «Solo sé que NO sé nada».

Al final del proceso, en el recuento final de los votos, la alcaldesa se mantuvo en su puesto: subió más treinta puntos entre las encuestas y logró remontar el resultado final en poco más de un mes. Con ello ganó la contienda por un estrecho margen, contra todo pronóstico. El No derrotó al Sí gracias a la imparable epidemia de buen humor que se viralizó gracias a activistas utilizando referencias en clave pop de modo consciente y a sabiendas de su gran conexión emocional con otros ciudadanos de similares condiciones. Lo explica Pierre:

Hice los memes sobre la base de mis propios repertorios emocionales, pero también yo sé cuándo algo va a tocar a alguien. Eso me lo ha dado la publicidad, supongo, Y recurrí a ellos porque ya estaban ahí y los tomé prestados. Me sumé a la fuerza. Sí creo que es un canal de comunicación política 
importante. Y está en manos de gente como yo, a favor de una causa justa (entrevista personal, julio de 2017).

\section{La plataforma «Alerta contra policías con cámaras de velocidad»}

La narrativa personal de Antonio Castro, y el storytelling digital que desarrolló en la plataforma de Facebook Alerta contra policías con cámaras de seguridad convergieron para activar una fugaz y exitosa movilización ciudadana, resuelta con intensas acciones online apoyadas en ocasionales protestas en la calle. Estas protestas se dieron ante las instituciones que tuvieron a cargo la implementación de un programa municipal de multas por excesiva velocidad de conductores de autos, y que, si bien estuvo impulsada por la gestión de la mencionada alcaldesa Villarán, en la práctica fue en la Policía donde se encontraron las acciones ilícitas que precipitaron luego su anulación y la devolución el dinero que se recaudó con las multas.

Antonio cuenta con un pregrado en Ciencias de la Comunicación y un MBA en el extranjero, y considera que el programa de multas fue «diseñado para recaudar dinero y no para proteger vidas». Así lo expresó a la prensa, de forma pública, a las pocas horas de abrir la cuenta en Facebook, en 2013, y que, por su veloz impacto, concitaría no solo la adhesión de cientos de miles de activistas sino también la atención de los medios de comunicación, los que solicitaron permanentemente sus impresiones. Con todo ello, su campaña se convirtió en una poderosa plataforma de movilización con gran capacidad de influencia.

También conocido como El hombre de las fotopapeletas, Antonio inició su campaña denunciando la imposición de multas por la Policía y la Municipalidad de Lima, quienes emplearon un cuestionado sistema de fotografías para registrar exceso de velocidad. Antonio estaba lejos en ese momento de querer hacer política ni intervenir en asuntos municipales, pero la evidente ilegalidad de la situación y el claro abuso de las autoridades lo llevaron de la indignación a la acción. Lo explica en una entrevista personal: «Los peruanos se quejan de todo, pero no toman acciones. '¡Basta de siempre estar quejándonos; hay que hacer algo! ¡Hay que comprometerse!', me dije. Y eso fue lo que hice» (entrevista personal, mayo de 2014).

Aun cuando sus labores profesionales no le permitían mucha atención, Antonio creó la página en Facebook Alerta contra policías con cámaras de velocidad «porque estaba realmente enojado y ofendido». El objetivo de su acción era, inicialmente, el crear un mapa de cámaras de velocidad en tiempo 
real y, tras la identificación de esos puntos, advertir a los conductores sobre el fraude. Se concentró específicamente en las denominadas señales fantasmas, un término acuñado entre los que protestaban en Facebook y que se refiere a un sistema de multas basado en letreros con advertencias colocados solo por algunas horas de menor tránsito, y luego levantados, con lo que los conductores no tenían cómo saber que había límites de velocidad. La División de Investigación Criminalística de la Policía estableció que hubo mafias enquistadas en el Sistema de Administración Tributaria (SAT) de la Municipalidad de Lima, que montaban estas farsas.

Antonio relata que, tras la apertura de su cuenta, pasó dos horas en una cena identificando a amigos de Facebook que podrían estar interesados en su causa. Entre sus novecientos contactos, encontró aproximadamente cuatrocientos a los que invitó. «Cuando regresé de la cena, me sorprendí», dijo. La respuesta fue inmediata. Para la medianoche de ese mismo día, tenía 4200 seguidores. Poco después, la página había llegado a 45800 , grupo con el que a la postre realizó reuniones regulares y organizó manifestaciones frente a la municipalidad. Antonio evoca:

Mi compromiso era enorme en ese momento. Quería tratar el problema de manera integral, para entender cómo estaba sucediendo, con quién estábamos tratando. Así que decidí dejar mi negocio para dedicar mi tiempo completo a responder correos electrónicos, a investigar y a reunirme con expertos que pudieran ayudar al grupo. Afortunadamente, soy empresario, así que podía delegar mis deberes cotidianos (entrevista personal, 5 de mayo de 2014).

El activismo de Antonio y otros usuarios, mediante su cuenta de Facebook y otros sitios de internet, propició que también se produjeran memes parodiando el sistema de cobros pernicioso. Uno de ellos, por ejemplo, empleó referencias locales como la de la Casa Matusita - un edificio comercial abandonado y supuestamente habitado por fantasmas - con el texto que decía: «Nueva sede para el cobro de multas por velocidad», así como inevitables referencias a la película Los Cazafantasmas junto a la frase: «Nuevo equipo contra las fotopapeletas». La ironía también se dirigió contra la alcaldesa en funciones - anecdóticamente, la misma que salvó la revocatoria con una campaña de memes-, dedicándole un meme con su rostro sonriente y una frase que recordaba el proceso.

Antonio intentó infructuosamente ponerse en contacto con funcionarios del SAT para presentar personalmente las quejas. Sin embargo, fue una nota publicada en un sitio web de noticias locales, Terra, lo que le permitió llamar la atención. Tras ello fue contactado con frecuencia para ser entrevistado en radio y televisión. 


\section{Figura 4}
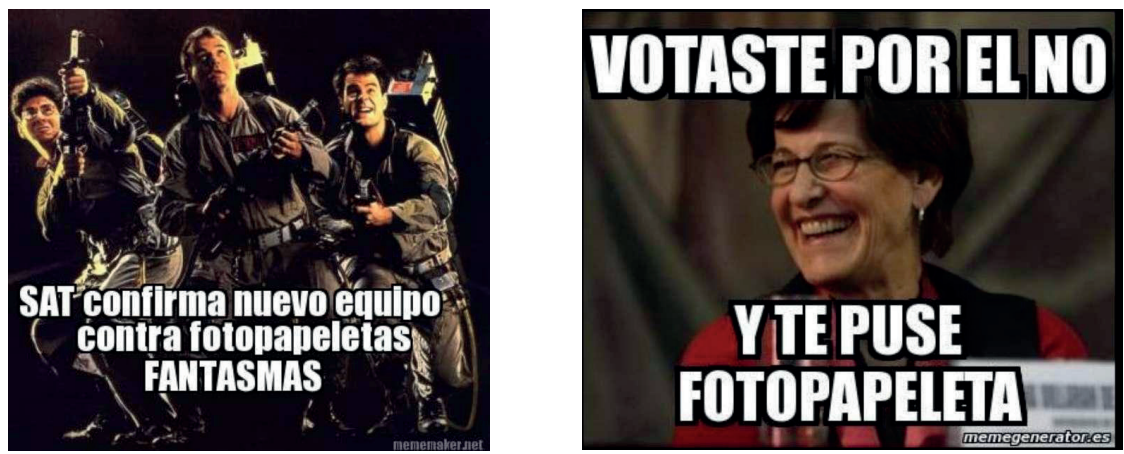

Así, le fue fácil colocar en el diario El Comercio —el más influyente en el Perúuna columna de opinión firmada sobre el tema. Fue entonces cuando personal de la oficina de la alcaldesa decidió suspender el programa, anulando más de 20000 papeletas y, finalmente, devolver más de 2 millones de soles (más de US\$ $588000)$ en multas a los conductores.

«No robes: los políticos odian la competencia». Discusión sobre el uso de memes y el activismo de la política

Los dos casos de estudio descritos evidencian fenómenos de movilización ciudadana que involucraron a decenas de miles de personas en Lima, a juzgar por las afiliaciones que tuvieron en cuentas de Facebook, los likes a sus publicaciones y la viralización de sus mensajes, gracias a que estas publicaciones - en su mayoría memes y eslóganes de campaña plenos de humor- fueron ampliamente compartidas por los activistas. Se puede apreciar también su influencia gracias a la cobertura que hicieron de ellos los medios de comunicación masiva, como diarios, radios y canales de televisión de señal abierta.

Para el caso de Meme No, en los últimos días de la campaña contra la revocatoria hubo decenas de miles de personas que salieron a las principales plazas de la ciudad, pronunciándose con las mismas consignas que se viralizaron en redes. En el caso de Alerta contra policías con cámaras de velocidad, si bien su plataforma fue principalmente digital, con publicaciones y enunciados de protesta en Facebook, también hubo grupos específicos de activistas que optaron por protestar frente a los locales de las oficinas municipales. La calle se constituyó así en la continuidad de lo que se propulsó en medios digitales. 
El recurso utilizado ampliamente en estas activaciones fue el meme. Este es un producto cultural que comenta, reflexiona y sienta posición sobre distintos aspectos de coyuntura, según la definición de Tomlinson (2004). Años antes de que los memes se convirtieran en un elemento cotidiano en la comunicación de las personas, Tomlinson sostenía que estos han de entenderse como fuerzas aceleradoras en la arena pública de causas que se quieren hacer notar entre los ciudadanos, haciéndolo desde una posición inicialmente trivial, ciertamente, por lo gracioso y cotidiano de su formulación, aunque sus mensajes comentan también, de forma aguda y corrosiva, aspectos críticos de la realidad política y social.

El término meme fue introducido por el biólogo Richad Dawkins en su libro El gen egoísta (1976). Shifman explica que Dawkins, como parte de su esfuerzo por aplicar la teoría evolutiva de las ciencias naturales al cambio cultural, define los memes como «pequeñas unidades de transmisión cultural, análogas a los genes, que se propagan de una persona a otra mediante la copia o imitación» (Shifman, 2014). Ejemplos de memes en el ensayo pionero de Dawkins son artefactos culturales como melodías, consignas políticas, y ropa de moda, así como creencias abstractas, como la misma idea de Dios.

La literatura más reciente sobre memes acierta en enfatizar prioritariamente sus cualidades virales. Nahon y Hemsley, en esa línea, citan la velocidad y la capacidad de alcance de sus mensajes a miles de personas, en simultáneo, como sus principales atributos (Nahon y Hemsley, 2013). Al mismo tiempo, Shifman explica su funcionamiento en las prácticas multimediáticas hoy en día: «Puede ser útil mirar a los memes no como simples ideas o fórmulas que se propagan eficientemente, sino también como conjuntos articulados de contenido» (Shifman, 2013).

Es lo que se puede encontrar en los despliegues virales de los dos casos peruanos. Los recursos de Meme No y de Alerta contra policías con cámaras de seguridad comparten características estructurales comunes que se pueden apreciar en su concepción, formulación y leguajes, así como en su tono cotidiano y popular. Por supuesto, se formulan, replican y transforman por la agencia de usuarios con una competencia estándar en el manejo de herramientas digitales. Y acentúan su viralidad cuando, tras ser compartidos por otros cientos de miles de usuarios, los medios tradicionales los incorporan como parte de su contenido informativo. Lo que Chadwick llama «procesos de hibridez mediática» (Chadwick, 2013). Un ejemplo: el meme de Alf, protagonista de la popular serie de televisión, con su frase característica, «No hay problema, Willy»; y su posterior tratamiento en la prensa televisiva de señal abierta. 


\section{Figura 5}

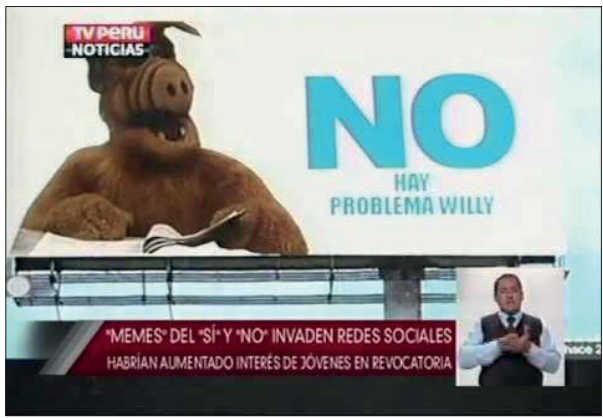

Vale decir que, si bien las investigaciones en memética se han venido centrando en la comprensión de su epidemiografía (Postill, 2014) o en el análisis de su contenido, «comparando los memes, o buscando sus elementos comunes» (Nahom y Hemsley, 2013), no se ha hecho análisis sobre el proceso de su constitución, ni documentado su vida social como artefacto. Sobre ello, y partir de lo observado, se pueden proponer cuatro etapas en su vida social:

\begin{tabular}{|c|c|c|c|}
\hline Conceptualización & Producción & Mediación & Viralización \\
\hline $\begin{array}{l}\text { Los activistas tecno- } \\
\text { sociales identifican un } \\
\text { insight crítico en los } \\
\text { debates ciudadanos y lo } \\
\text { asocian a un estado de } \\
\text { ánimo propiciado por } \\
\text { un popular aforismo o } \\
\text { frase mediática. Luego, } \\
\text { tienden una conjunción } \\
\text { emocional entre ambos, } \\
\text { concentrándola en un } \\
\text { meme. }\end{array}$ & $\begin{array}{l}\text { Diseñan los elementos } \\
\text { meméticos utilizando } \\
\text { herramientas o dispo- } \\
\text { sitivos digitales, tales } \\
\text { como los programas } \\
\text { Photoshop, Illustrator, } \\
\text { o compositores como } \\
\text { memegenerator.com. } \\
\text { Se guarda riguroso } \\
\text { respeto por la imagen } \\
\text { del personaje mediá- } \\
\text { tico referencial. }\end{array}$ & $\begin{array}{l}\text { El meme se publica } \\
\text { en los medios } \\
\text { sociales digitales, } \\
\text { priorizando aque- } \\
\text { llos que convocan } \\
\text { a la mayor masa } \\
\text { crítica de sus comu- } \\
\text { nidades. }\end{array}$ & $\begin{array}{l}\text { El meme se replica } \\
\mathrm{m} \text { a s i v a m e n t e } \\
\text { mediante los boto- } \\
\text { nes «Me gusta» y } \\
\text { «Compartir» por } \\
\text { miles de usuarios } \\
\text { que no se cono- } \\
\text { cen entre sí, pero } \\
\text { que comparten la } \\
\text { causa o el estado } \\
\text { de indignación. }\end{array}$ \\
\hline
\end{tabular}

En contextos distintos, con otras circunstancias cívicas y políticas condicionando la vida social, como en China, autores como Marcella Szablewicz encuentran que los memes son estructuras de sentimiento que promueven identidades alternativas, defendiendo las ideas principales de sus adherentes y divulgando sus valores intrínsecos. En su estudio sobre la red de relacionamiento social Weibo, ella considera que son los jóvenes internautas, dados a llamarse 
«perdedores» (losers), quienes los usan para responder de manera creativa a los patrones normativos que circulan entre ellos, por ejemplo, los de los hombres exitosos, adinerados o guapos o los de las mujeres de rasgos anglosajones, delgadas y «bien parecidas». Ante ello, los memes en China son usados por los que se asumen «perdedores» para resaltar su condición de pobres, pequeños y feos, condiciones que reivindican como propias de su vida ordinaria. Así, Szablewicz postula que los memes muestran una política del potencial, creando formas de resistencia contra las normas imperantes (Szablewicz, 2015).

En circunstancias críticas como las expuestas en el Perú, podemos apreciar que acudimos, en efecto, a la misma lógica de la «política del potencial» que sugiere Szablewicz. Shifman es más asertivo, pues sugiere que los memes «representan una nueva forma de participación política» (Shifman, 2013). E insiste, por lo demás, en que, si bien la ciencia política tradicional se ha centrado en el estudio de la participación y de prácticas más fácilmente medibles — como el voto o la afiliación a organizaciones - una ciencia política contemporánea tendría que abordar acciones más cotidianas y rutinarias, sobre todo aquellas que levantan banderas de causas puntuales y de condena a la corrupción sufrida en la vida diaria.

Vale considerar, finalmente, el modo en que la producción y viralización de memes puede llevar también un carácter ritual. Burroughs descubrió, por ejemplo, que durante la campaña de reelección de 2012 del presidente Obama en los Estados Unidos, trollearlo - acción de torpedear a una persona, plataforma o causa mediante contramensajes calumniosos o ridiculizantes - se convirtió en una práctica que puede considerarse como una «política agonística de la decepción» (Burrougs, 2013). Es evidente que, en los casos peruanos revisados, el trolleo fue una forma activa de transmitir desencanto y a la vez de política de potencial, dadas las pretensiones de imposición mercantilista en un caso, y de ramplón ejercicio de corrupción en el otro.

\section{CONCLUSIÓN}

En el Perú, la experiencia reciente de vivir en democracia y con política parlamentaria está representando duros cuadros de desencanto y decepción. En este escenario surgen las movilizaciones y los movimientos que hemos presenciado en los últimos años. Se producen trasladando insatisfacciones en las plataformas digitales y en la movilización física, con resultados que muchas veces cambian el statu quo. Gerbaudo lo describe de esta manera: son sectores que tienen el proyecto de reapropiarse del espacio público y elevar la voz con un liderazgo soft, 
gracias, entre otros recursos, a la «coreografía emocional» que sus organizaciones montan dramáticamente en distintos ámbitos públicos (Gerbaudo, 2012).

El activismo ciudadano de hoy nos está llevando por la senda de la política de la cultura popular, o poplítica, en la que los elementos emocionales y performáticos que se desarrollan están constituyendo nuevos rituales mediáticos con clara significación social, haciendo posible, además, la visibilización de problemáticas sociales que de otro modo podrían pasar desapercibidos, quedar pendientes o, incluso, impunes.

\section{REFERENCIAS}

Barassi, Veronica (2017). Digital Citizens? Data Traces and Family Life. Contemporary Social Science, 12, 1-2. https://doi.org/10.1080/21582041.2017.1338353

Bastos, Marco, Raquel Recuero y Gabriela Zago (2014). Taking Tweets to the Streets. A Spatial Analysis of Vinegar Protest in Brasil. First Monday, 19(3). https://doi. org/10.5210/fm.v19i3.5227

Burroughs, Benjamin (2013). FJC-165: Obama Trolling. Fibreculture Journal, 22.

Carling, Ryan, Matthew Singer y Elizabeth Zeigmeister (2015). The Latin American Voter. Michigan: University of Michigan Press. https://doi.org/10.3998/ mpub.8402589

Castells, Manuel (2012). Networks of Outrage and Hope: Social movements in the internet age. Cambridge: Polity.

Chadwick, Andrew (2013). Hybrid Media Systems, Politics and Power. Oxford: Oxford University Press. https://doi.org/10.1093/acprof:oso/9780199759477.001.0001

Dahl, Robert (1957). The Concept of Power. Behavioral Sciences, 2. https://doi. org/10.1002/bs.3830020303

Dawkings, Richard (1976). The Selfish Gene. Oxford: Oxford University Press.

Earl, Jennifer y Katrina Kimport (2011). Digitally Enabled Social Change. Londres: MIT Press.

Etling, Bruce, Robert Faris y John Palfrey (2010). Political Change in the Digital Age. The Fragility and Promise of Online Organizing. SAIS Review, Summer-Fall.

Fernández-Maldonado, Enrique (2015). La rebelión de los pulpines. Jóvenes, trabajo y política. Lima: Otra Mirada.

Gerbaudo, Paolo y Emiliano Treré (2015). In Search of the «We» of Social Media Activism: introduction to the special issue on social media and protest identities. 
Información, Comunicación y Sociedad, 18(8), 865-871. https://doi.org/10.108 0/1369118X.2015.1043319

Halupka, Max (2018). The Legitimization of Clicktivism. Australian Journal of Political Science, 53(1), 130-141.

Haynes, Nell (2016). Social Media in Northern Chile. Posting the extraordinarily ordinary. Londres: UCL. https://doi.org/10.2307/j.ctt1g69xv2

Juris, Jeffrey (2008). Networking futures. The movements against corporate globalization. Durham: Duke University Press. https://doi.org/10.1215/9780822389170

Karpf, David (2010). Online Political Mobilization from the Advocacy Group's Perspective: Looking Beyond Clicktivism. Policy and Internet, 2(4), 7-41.

Kavada, Anastassia (2015). Creating the Collective: social media, the Occupy Movement and its constitution as a collective actor. Information, Communication \& Society, 18(8), 872-886. https://doi.org/10.1080/1369118X.2015.1043318

Miller, Daniel, Elisabetta Costa, Nell Haynes, Tom McDonald, Razvan Nicolescu, Jolynna Sinnanan y Juliano Spyer (2016). How the World Changed Social Media. Londres: UCL. https://doi.org/10.2307/j.ctt1g69z35

Monteverde, Arnau, Antonio Calleja-López, Miguel Aguilera, Xabier E. Barandarián y John Postill (2015). Multitudinous Identities: a qualitative and network analysis of the $15 \mathrm{M}$ collective identity. Information, Communication \& Society, 18(8), 930-950. https://doi.org/10.1080/1369118X.2015.1043315

Nahon, Karine y Jeff Hemsley (2013). Going Viral. Cambridge: Polity Press.

Naim, Moisés (2015). El fin del poder. Barcelona: Random House.

Parikka, Jussi (2007). Contagion and Repetition: On the Viral Logic of Network Culture. Ephermera: Theory \& Politics in Organizations, 7(2), 287-308.

Pink, Sarah, Heather Horst, John Postill, Larissa Hjorth, Tania Lewis y Jo Tacchi (2016). Digital Ethnography. Principles and Practices. Londres: Sage.

Porto, Mauro y João Brant (2015). Social Media and the 2013 Protests in Brazil. The Contradictory Nature of Political Mobilization in the Digital Era. En Lina Dencik y Oliver Leistert (eds.), Critical Perspectives on Social Media and Protest. Between Control and Emancipation (pp. 181-200). Londres y Nueva York: Rowman and Littlefield.

Postill, John (2013). Digital Politics and Political Engagement. En Daniel Miller y Heather Horst (eds.), Digital Anthropology (pp. 165-184). Londres: Bloomsbury.

Postill, John (2014). Democracy in an Age of Viral Reality. A Media Epidemiography of Spain's Indignados Movement. Ethnography, 15(1), 50-68. https://doi. org/10.1177/1466138113502513 
Postill, John (2018). The Rise of Nerd Politics. Digital Activism and Political Change. Chicago: Pluto Press. https://doi.org/10.2307/j.ctv4ncp67

Postill, John y Sarah Pink (2012). Social Media Ethnography: The Digital Researcher in a Messy Web. Media International Australia, 145, 123-134. https://doi. org/10.1177/1329878X1214500114

Sartori, Giovanni (2002). La política. Lógica y método en las ciencias sociales. México: FCE.

Scherman, Andrés, Arturo Arriagada y Sebastián Valenzuela (2013). La protesta en la era de las redes sociales. El caso chileno. En A. Arriagada y P. Navia, Intermedios: Medios de comunicación y democracia en Chile (pp. 181-199). Santiago: UDP.

Shifman, Limor (2014). Memes in Digital Culture. Cambridge y Londres: The MIT Essential Knowledge Series.

Szablewicz, Marcella (2015). The losers of China's Internet. En Gouin Yang (ed.), China's Contested Internet. Copenhague: NIAS Press.

Tomlinson (2004). Memes and Metaculture: the Politics of Discourse Circulation in Fiji. The Australian Journal of Anthropology, 15(2), 185-197. https://doi. org/10.1111/j.1835-9310.2004.tb00251.x

Vivianne, Sonja (2016). Digital Identity and Everyday Activism. Sharing public stories with networked publics. Nueva York: Springer.

Yang, Goubin (2016). The Commercialization and Digitization of Social Movement Society. Contemporary Sociology, 45(2), 120-125. https://doi. org/10.1177/0094306116629409 